\title{
Influence of pulp type on the three-dimensional thermomechanical convertibility of paperboard
}

\author{
Teija Laukala $\cdot$ Sami-Seppo Ovaska $\cdot$ Panu Tanninen · Antti Pesonen • \\ Juha Jordan $\cdot$ Kaj Backfolk
}

Received: 24 August 2018/ Accepted: 25 January 2019/Published online: 6 February 2019

(C) The Author(s) 2019

\begin{abstract}
This study examines the effect of pulp type on the formability and elongation of paperboard, which are of key importance when producing 3D packages. Material performance was studied with a press-forming machine using laboratory handsheets as substrates. The handsheets were prepared from bleached softwood and hardwood kraft pulps, chemithermomechanical pulp, recycled newsprint, and mixtures of birch kraft and other pulps. The effect of microfibrillated cellulose (MFC) on substrate properties and material formability was also investigated. The 3D elongation of MFC-free handsheets varied between 1.2 and 5.5\%. Depending on the pulp type and sheet composition, three essential sheet properties were recognized. These properties were bulk, elastic modulus and bending stiffness, the first two of which
\end{abstract}

affect material bending stiffness. Sheets made from softwood fibers were superior to other samples, but their low bending stiffness resulted in distortion of formed trays. A partial replacement of birch kraft with recycled newsprint did not lead to a loss of sheet extensibility, which suggests that the interactions between the converting tools and the substrate have a great effect on material convertibility. Scanning electron micrographs showed that the pulp type affects the mechanism behind fracture initiation. The ability of MFC to increase extensibility was limited to mechanical pulps, indicating the important role of the main pulp component in defining tensile properties.

T. Laukala $(\varangle) \cdot$ S.-S. Ovaska $\cdot$ P. Tanninen .

A. Pesonen · J. Jordan · K. Backfolk

School of Energy Systems, Group of Packaging

Technology, Lappeenranta University of Technology,

P. O. Box 20, 53851 Lappeenranta, Finland

e-mail: teija.laukala@lut.fi 


\section{Graphical abstract}

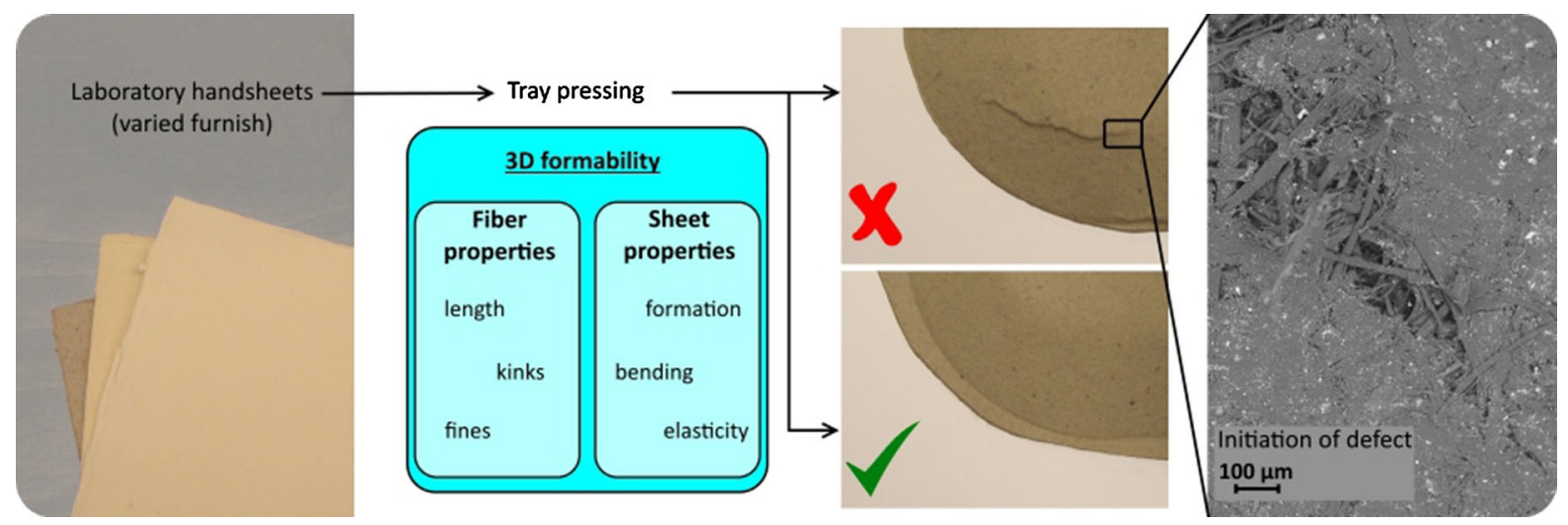

Keywords Elongation - Formability · Paperboard · Press forming $\cdot$ Pulp

\section{Introduction}

Wood-fiber-based packaging materials have several significant benefits such as better sustainability and good printability compared to most common thermoplastics. These properties explain the growing interest in paperboard packages, but complex shapes cannot be produced because of factors such as moderate elongation, differences in physical properties between the machine-direction and cross-direction, and local fluctuation of tensile properties due to material heterogeneity and the nature of sheet formation. Paperboard packages are also susceptible to dimensional variation due to their limited rigidity and hygroscopic nature.

Mechanical and chemical fibers differ in their physical properties. Mechanical fibers are stiffer than chemical fibers, especially in wet conditions. Both mechanical pulp and chemi-thermomechanical pulp (CTMP) provide bulk, which is an essential material property for many converting processes. Lignin decreases the risk of dimensional changes in paper (Koubaa et al. 1996), which suggests that problems related to blank curling, for example, could be reduced if the paperboard contains mechanical pulp. Given ecological and economical aspects such as better yield and chlorine-free bleaching, CTMP and mechanical pulp are interesting raw materials for the manufacture of formable paperboard, although purity issues may limit their usage in food packaging applications. Purity problems are particularly acute in recycled pulp due to migration issues. Interest in using microfibrillated cellulose (MFC) in paperboard grades has grown in recent years, since MFC makes it possible to decrease grammage without loss of strength (Kajanto and Kosonen 2012).

The stretch potential of the fibers and inter-fiber bonding affect the sheet extensibility. Stretching can be either irreversible or reversible, and at the fiber level, stretching is affected, for example, by the fibril angle and the axial compressive strain, which shortens fibers lengthwise (Seth 2005). Stretching is caused by outer forces that at the microfibrillar level lead to reorientation of microfibrils or orientation of the cellulose (Altaner et al. 2014). The effects of pulp type and the properties of the fibers and fiber network on 3D formability are known to some extent (Hauptmann et al. 2015; Vishtal and Retulainen 2012). The denser areas of a paperboard have been suggested to be locally more extensible (Hagman and Nygårds 2012), due to better interfiber bonding counteracting the emergence of a stress failure. There is evidence that a combination of a higher beating degree and an enzymatic treatment with xylanase may increase paper elongation (Fillinger 2016). However, xylanase treatment has no influence on paper elongation if measurement is done using a tensile tester (Saukkonen et al. 2014), which suggests that the role of mechanical treatment of fibers is dominant. This conclusion is supported by the work of Seth (2005), who proposed two production-related factors that can be used to control sheet extensibility: mechanical treatment of the fibers and degree of sheet shrinkage during drying, although the properties of the single fibers are 
emphasized after sufficient bonding is achieved. In addition, the results of Mayhood et al. (1962) suggest that the degree of fiber plasticization is affected by the beating degree of the pulp, which again emphasizes the significance of mechanical treatment. Moreover, surface treatments with MFC, natural polymers such as agar or gelatin, and polylactic acid have been reported to increase the extensibility of fiber-based substrates (Lavoine et al. 2014; Vishtal et al. 2015; Rhim and Kim 2009; Ketola et al. 2018).

In press-forming, which is one method for producing packages from paperboard, the rigidity of trays is controlled by feeding the blank into the press so that the longer side of the blank is parallel to the machine direction (MD) (Leminen et al. 2013). Either the female or male tool is heated, or in some cases both tools, which aids plastic deformation. Moisture content is a significant factor, since it affects the friction between the substrate and the converting tool, which may have a drastic influence on the success of the forming process. Moreover, the presence of water softens the material by weakening the interfiber bonding and hydrogen bonds between cellulose molecules, which in turn leads to a decrease in the glass transition temperature $\left(\mathrm{T}_{\mathrm{g}}\right)$. Moisture also affects the elastic modulus, which should be low in order to achieve good formability (Kajanto 2003).

The work of Salmén (1993) shows that the $T_{g}$ of amorphous polymers such as hemicellulose and lignin, in particular, decreases when the moisture content increases. At a moisture content of $0 \%$, the $\mathrm{T}_{\mathrm{g}}$ is over $200{ }^{\circ} \mathrm{C}$, but a reduction of almost $100{ }^{\circ} \mathrm{C}$ can be expected if the moisture content increases to $10 \%$. For dry cellulose, the $\mathrm{T}_{\mathrm{g}}$ is approximately $200-230{ }^{\circ} \mathrm{C}$ depending on the crystallinity. When the sample is moisturized to $10 \%$ water content, the $\mathrm{T}_{\mathrm{g}}$ of amorphous cellulose is close to $100{ }^{\circ} \mathrm{C}$, but only about $-40{ }^{\circ} \mathrm{C}$ if the degree of crystallinity is $80 \%$. The dramatic changes in polymer softening as a result of increased moisture content affect the physical properties, with a decrease in strength properties and elastic modulus (Waterhouse 1984; Gunderson and Considine 1986). The reduced elastic modulus is beneficial for 3D forming due to its effect on bending stiffness (Kajanto 2003; Hauptmann et al. 2015). Additionally, an increase in strain-at-break and creep can be seen after moisturizing the material (Alfthan 2004; Rhim 2010).
The physical properties of a substrate are typically reported based on common standardized laboratory measurements, but there is evidence that a laboratory tensile tester is not capable of predicting material behavior in 3D forming (Lyytikäinen 2015; Leminen et al. 2016). This can be ascribed to the more complex tensile, shear and compressive forces that occur during rapid 3D forming. The physico-mechanical properties of fiber-based substrates are thus likely to change in a converting environment, not least due to higher moisture content decreasing the elastic modulus (Salmén and Back 1980; Kajanto 2003). Indeed, it has been claimed that the strain-at-break of paper can increase by $20 \%$ if the moisture content of the sample is increased from 6 to 14\% (Linvill and Östlund 2014). This change is related to alterations within the fiber wall and bonds between the fibers due to change in the amount of free water (Vishtal and Retulainen 2014). Östlund et al. (2011) reported that the strain-at-break values of commercial paperboards vary within the range $1.1-4.2 \%$, but according to Tanninen et al. (2017a), a complex multilayered structure with several fiber and polymer layers may result in higher extensibility. Tanninen et al. (2017b) found that a paperboard with a machine-directional strain-at-break value of $1.7 \%$ (RH 50\%) had an elongation of approximately $6 \%$ (RH $80 \%$ ) in press-forming. It was suggested that the observed difference was due to higher sample moisture content, different velocity during straining, and a different length-to-width ratio of the sample. Obviously, the complex forces and tool-substrate interactions in the forming process also affected the result.

Previous research has mostly focused on improving the extensibility of ready-made paperboard or testing commercial paperboard samples. First, it should be noted that excessive extensibility can be detrimental, since it may in extreme cases lead to severe distortion of a pressed form as reported by Ovaska et al. (2018a, b). Several mechanical and chemical treatments to increase extensibility have been proposed. Examples of mechanical treatments include creping, which can result in elongation of $15-300 \%$, compaction, which increases elongation by up to $10-15 \%$, and patterning of the paperboard with a creaser (Vishtal and Retulainen 2012; Panthi 2016). Strand et al. (2017) studied the effect of wet-end additives on paper elongation and found that certain combinations of carboxymethyl cellulose and cationic starch helped 
to maintain paper elongation after unrestrained drying, although the studied polysaccharides had only a very small effect on elongation if restrained drying was used. Recent findings suggest that MFC improves paper elongation. This result was ascribed to increased drying shrinkage under unrestrained drying (Ketola et al. 2018) and formation of a morphologically defect-free fibrous network (González et al. 2014). Although clearly a pertinent topic, only a very small number of fundamental studies are available on the influence of pulp type and fiber composition on 3D elongation of fiber-based formable materials.

This study aims to provide an overview of the effect of pulp type on paperboard extensibility in a 3D forming process. In the work, special attention is paid to the ability of laboratory experiments to predict material formability and 3D elongation in pressforming. The paper concludes with a brief discussion of the ideal pulp composition of formable board.

\section{Materials and methods}

\section{Materials}

Two dried market bleached kraft pulps, one hardwood (HW) and one softwood (SW), and dried bleached chemi-thermomechanical pulp (CTMP) were provided by the Stora Enso Kaukopää mill (Imatra, Finland). Recycled pulp (RCF) was acquired from newspapers printed by Kaakon Viestintä Oy (Mikkeli, Finland). Wood-pulp based microfibrillated cellulose (Celish KY100G, Daicel FineChem Ltd., Japan) was also used in the experiments. Mean length and diameter of Celish KY100G have been reported to be $350 \mu \mathrm{m}$ and $15 \mu \mathrm{m}$, respectively (Tatsumi et al. 2002).

The reference material used in the experiments was a commercial hydrophobically sized three-layer paperboard (Trayforma Natura 190 gsm, Stora Enso, Imatra, Finland), which is used in, for example, pressed trays. The outer layers of the paperboard consist of kraft pulp, but the middle layer is manufactured from a mixture of kraft pulp and CTMP.

\section{Pulp preparation and testing}

The wood-free pulps and CTMP were all shredded, soaked in water and disintegrated according to ISO
5264-1:1979 with a Valley beater at the targeted consistency of $15.7 \mathrm{~g} / \mathrm{l}$. The wood-free pulps were refined to ${ }^{\circ} \mathrm{SR}$ levels of 15 (SW) and 20 (HW). The ${ }^{\circ} \mathrm{SR}$ levels were chosen in order to retain the capability of the pulps to provide bulk and to control the amount of fines. With the CTMP, the ${ }^{\circ} \mathrm{SR}$ level was found to be 25 after the disintegration phase only, and no further beating was applied. MFC was heavily diluted with water and mixed with a Diaf-type mixer prior to blending with the conventional pulps. Blending was carried out with a vertical mixer equipped with an impeller that created an axial flow. Drainability of the pulp was determined using the Schopper-Riegler method (ISO 5267-1:1999).

The RCF was prepared with a disintegrator (L\&W Pulp Disintegrator, Lorentzen \& Wettre, Kista, Sweden) after soaking the shredded paper in water for four hours. One batch consisted of $60 \mathrm{~g}$ of dry paper and the total volume was $2700 \mathrm{ml}$. The number of revolutions was set to 10,000 . The ${ }^{\circ} \mathrm{SR}$ level of the RCF after disintegration was 38 .

The pulp suspensions were diluted with water (approximately $0.1 \mathrm{~g}$ fiber in $100 \mathrm{ml}$ of fiber suspension) and analyzed with an L\&W Fiber Tester (Lorentzen \& Wettre, Kista, Sweden). The following properties were determined: fiber length and width, fines content and kink index. In addition to unmixed pulps, pulp mixtures (Table 1) were also analyzed, with the exception of MFC-containing suspensions, due to the limited capability of the Fiber Tester to recognize small fiber fractions. Since the SW used initially had good tensile properties in comparison with the other pulps (see Table 4 for values), the effect of MFC addition was investigated only on HW, CTMP and RCF.

Table 1 Compositions of prepared pulp suspensions (wt $\%$ of pulp in water)

\begin{tabular}{lllll}
\hline Pulp type & HW & SW & CTMP & RCF \\
\hline HW & 100 & $75: 25$ & $75: 25$ & $75: 25$ \\
& & $50: 50$ & $50: 50$ & $50: 50$ \\
& & $25: 75$ & $25: 75$ & $25: 75$ \\
& & $0: 100$ & $0: 100$ & $0: 100$ \\
MFC & $5: 95$ & - & $5: 95$ & $5: 95$ \\
\hline
\end{tabular}


Handsheet preparation, physical testing, and imaging

Handsheets were prepared from the pulps according to ISO 5269-1:2005 with the exceptions that the targeted grammage for the handsheets was $190 \mathrm{~g} / \mathrm{m}^{2}$ and the wet-pressed handsheets were dried with a drying drum instead of drying plates in order to maintain sheet extensibility. Physical properties of the handsheets were tested at $23{ }^{\circ} \mathrm{C}$ and $50 \%$ relative humidity. Grammage was measured according to ISO 536:2012 and thickness according to ISO 534:2011. Bendtsen porosity was measured with an L\&W Bendtsen Tester (Lorentzen \& Wettre, Kista, Sweden) in accordance with ISO 8791-2013. Tensile properties were measured with an L\&W Tensile Tester (Lorentzen \& Wettre, Kista, Sweden) according to ISO 1924-2:2008/3:2005. Bending stiffness was measured with an L\&W Bending Tester (Lorentzen \& Wettre, Kista, Sweden) according to ISO 2493-1:2010.

A scanning electron microscope (SEM, Hitachi SU3500 equipped with a wolfram filament and a Hitachi BSE detector) was used to acquire images of selected handsheets and paperboard trays. The microscope was operated in variable pressure mode (VP SEM) using $30 \mathrm{~Pa}$ pressure, BSE-comp mode, and a working distance of ca. $10 \mathrm{~mm}$.

Press-forming trials

The success of 3D forming is highly dependent on substrate moisture content, since water has a plasticizing effect that changes the structure of the polymers during heating, but moisture content also affects strength properties and increases paper friction, which may affect blank sliding kinetics during forming (Kawasima et al. 2008; Vishtal and Retulainen 2012). Tanninen et al. (2014) recommend that the moisture level in a press-forming process should be $9-11 \%$, although less blank curling can be expected at lower moisture levels, at a cost of formability (Ovaska et al. 2018a, 2018b). Since good formability was targeted, the recommendation of Tanninen et al. (2014) was followed in this investigation.

The moisture content of the handsheets was determined prior to press-forming trials at RH 20, 50, and $80 \%$ (T: $23{ }^{\circ} \mathrm{C}$ ) in order to find the targeted moisture level. At RH 20\%, the moisture content varied between $6.2 \%$ and $8.3 \%$, and between 8.5 and $11.7 \%$ at RH 50\%. At RH 80\%, the average moisture content of all samples was $\geq 13.8 \%$, indicating that the samples were too moist for forming trials.

The pre-conditioned $\left(23{ }^{\circ} \mathrm{C}\right.$, RH 50\%) blanks were converted into rectangular trays at LUT Packaging Line using a MiniMould tool (see Fig. 1) that had earlier been developed for press-forming laboratory handsheets. The experiments were carried out in fixedblank mode, which made it possible to determine the 3D material elongation based on the maximum forming depth without ruptures. The press-forming method and the elongation calculation are described in detail elsewhere (Tanninen et al. 2017b). The experiments were carried out at female tool temperature of $80{ }^{\circ} \mathrm{C}$. The male tool was not heated during the experiments.

\section{Results}

Pulp analysis results are shown in Table 2. Table 3 shows the water-substrate interactions of the studied materials, and the physical properties of the handsheets are given in Table 4.

The sheets made of wood-free pulps and CTMP were highly hydrophilic and absorbent, with their contact angles being $41^{\circ}-45^{\circ}$. RCF absorbed water slowly and the contact angle of water was $88^{\circ}$, which was ascribed to impurities such as inks, sizes, and typical paper chemicals present in the sample. The reference paperboard was hydrophobic, due to internal

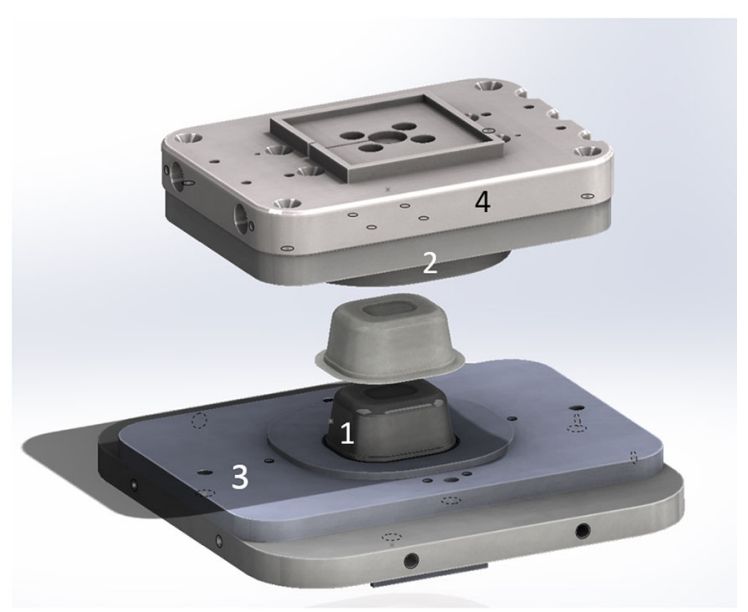

Fig. 1 Press-forming tool set: (1) the male mold, (2) the female mold, (3) the rim tool and (4) the heating unit 
Table 2 Results of pulp analysis. The reference material was a commercial hydrophobically sized three-layer paperboard (190 gsm) that was repulped

\begin{tabular}{llllc}
\hline Samples & Length, $(\mathrm{mm})$ & Width, $(\mu \mathrm{m})$ & Kink index & Fines, $(\%)$ \\
\hline Reference & 1.10 & 22.2 & 1.00 & 1.9 \\
HW & 0.92 & 19.7 & 1.37 & 6.4 \\
SW & 1.87 & 27.4 & 1.31 & 8.2 \\
CTMP & 1.62 & 39.6 & 0.55 & 11.7 \\
RCF & 1.16 & 30.6 & 1.08 & 23.2 \\
HW:SW & & & & \\
75:25 & 1.03 & 20.2 & 1.53 & 6.3 \\
50:50 & 1.25 & 21.6 & 1.47 & 5.8 \\
25:75 & 1.22 & 22.2 & 1.58 & 10.0 \\
$H W: C T M P$ & & & & \\
$75: 25$ & 0.99 & 20.8 & 1.50 & 7.0 \\
50:50 & 1.03 & 23.1 & 1.46 & 7.9 \\
25:75 & 1.18 & 28.4 & 1.23 & 10.1 \\
$H W: R C F$ & & & & 11.0 \\
$75: 25$ & 1.08 & 25.3 & 1.34 & 14.5 \\
$50: 50$ & 1.01 & 22.0 & 1.55 & 15.0 \\
25:75 & 1.11 & 25.4 & 1.37 & \\
\hline
\end{tabular}

Table 3 Contact angle of water and time taken for full absorption of a water droplet

\begin{tabular}{llllll}
\hline Property & Reference & Hardwood kraft & Softwood kraft & CTMP & RCF \\
\hline Contact angle, $\left({ }^{\circ}\right)$ & 118 & 41 & 44 & 45 & 88 \\
Full absorption, $(\mathrm{s})$ & $>600$ & 0.30 & 0.15 & 0.12 & 17.20 \\
\hline
\end{tabular}

hydrophobic sizing, and the least absorptive of the tested sheets. However, these differences did not lead to major differences in sample moisture content prior to the forming, as noted earlier.

Comparison of pulps: effect of fiber morphology and air permeance on $3 \mathrm{D}$ elongation

Handsheets made of softwood kraft were found to have greater $3 \mathrm{D}$ elongation compared to hardwood kraft, CTMP, RCF, and the commercial reference material. The performance of CTMP and RCF did not differ substantially from the commercial reference material (Fig. 2). None of the studied parameters alone explained the $3 \mathrm{D}$ elongation potential in an obvious manner but attention was drawn to average fiber length and bulk. The effect of these factors is discussed later.

As regards dimensional differences of the fibers in the pulps, differences were observed mostly in the fines content. Otherwise the dimensional differences between the studied pulps were relatively minor. Despite the mild beating, the fines content of kraft pulps was higher than that of the commercial reference material, and the reference material fibers showed lower deformation than the fibers of both kraft pulps. The low deformation was ascribed to the fact that the commercial reference was manufactured from neverdried kraft pulp rather than dried kraft, which was the raw material of the laboratory handsheets. Differences between the deformation of dried and never-dried pulps have earlier been described by Giacomozzi and Joutsimo (2017).

CTMP and especially RCF contained a substantial quantity of fines, which is clearly due to the mechanical pulping process. The kink index of CTMP was lower than that of the commercial sample, and the fiber width was greater than that of the wood-free pulps. In the case of the reference board, the production process and presence of the related chemicals may explain the 
Table 4 Physical properties of the handsheets

\begin{tabular}{|c|c|c|c|c|c|c|c|c|}
\hline Samples & $\begin{array}{l}\text { Bulk, }\left(\mathrm{cm}^{3} /\right. \\
\text { g) }\end{array}$ & $\begin{array}{l}\text { Air } \\
\text { permeance, } \\
(\mathrm{ml} / \mathrm{min})\end{array}$ & $\begin{array}{l}\text { Specific } \\
\text { formation, } \\
(\sqrt{g s m})\end{array}$ & $\begin{array}{l}\text { Tensile } \\
\text { index, } \\
(\mathrm{Nm} / \mathrm{g})\end{array}$ & $\begin{array}{l}\text { Elastic } \\
\text { modulus, } \\
(\mathrm{MPa})\end{array}$ & $\begin{array}{l}\text { Strain at } \\
\text { break 2D, } \\
(\%)\end{array}$ & $\begin{array}{l}\text { Bending } \\
\text { stiffness, } \\
(\mathrm{mNm})\end{array}$ & $\begin{array}{l}\text { 3D- } \\
\text { elongation, } \\
(\%)\end{array}$ \\
\hline Reference & $1.19 \pm 0.01$ & $563 \pm 57.8$ & $0.74 \pm 0.00$ & $66.5 \pm 4.3$ & $5.7 \pm 2.4$ & $3.2 \pm 1.7$ & $5.2 \pm 2.4$ & 2.0 \\
\hline HW & $1.33 \pm 0.01$ & $465 \pm 98.6$ & $0.50 \pm 0.01$ & $45.5 \pm 3.6$ & $4.2 \pm 0.1$ & $3.6 \pm 0.5$ & $6.6 \pm 0.6$ & 3.0 \\
\hline SW & $1.53 \pm 0.04$ & $1279 \pm 198.5$ & $0.58 \pm 0.08$ & $32.2 \pm 2.6$ & $2.5 \pm 0.2$ & $4.0 \pm 0.4$ & $5.3 \pm 1.5$ & 5.5 \\
\hline CTMP & $2.50 \pm 0.02$ & $2157 \pm 67.9$ & $0.64 \pm 0.03$ & $18.7 \pm 1.2$ & $0.9 \pm 0.1$ & $1.8 \pm 0.1$ & $11.4 \pm 1.8$ & 1.2 \\
\hline \multicolumn{9}{|l|}{$H W: S W$} \\
\hline $75: 25$ & $1.38 \pm 0.01$ & $625 \pm 129.8$ & $0.46 \pm 0.01$ & $45.7 \pm 1.9$ & $3.9 \pm 0.1$ & $3.9 \pm 0.3$ & $6.1 \pm 1.0$ & 4.2 \\
\hline $50: 50$ & $1.57 \pm 0.04$ & $630 \pm 119.9$ & $0.68 \pm 0.08$ & $42.6 \pm 2.2$ & $3.3 \pm 0.2$ & $3.8 \pm 0.4$ & $8.6 \pm 1.8$ & 4.2 \\
\hline $25: 75$ & $1.54 \pm 0.02$ & $921 \pm 129.4$ & $0.44 \pm 0.10$ & $35.4 \pm 2.0$ & $2.8 \pm 0.2$ & $3.8 \pm 0.4$ & $7.1 \pm 1.0$ & 4.2 \\
\hline \multicolumn{9}{|c|}{$H W: C T M P$} \\
\hline $75: 25$ & $1.54 \pm 0.02$ & $670 \pm 78.6$ & $0.69 \pm 0.08$ & $35.9 \pm 2.9$ & $2.9 \pm 0.1$ & $2.9 \pm 0.4$ & $7.3 \pm 0.8$ & 2.5 \\
\hline $50: 50$ & $1.74 \pm 0.02$ & $971 \pm 130.0$ & $0.60 \pm 0.08$ & $31.7 \pm 0.9$ & $2.2 \pm 0.1$ & $2.7 \pm 0.2$ & $8.6 \pm 0.2$ & 2.0 \\
\hline $25: 75$ & $2.03 \pm 0.01$ & $1394 \pm 136.1$ & $0.59 \pm 0.13$ & $26.0 \pm 1.3$ & $1.6 \pm 0.1$ & $2.3 \pm 0.2$ & $8.1 \pm 1.0$ & 2.0 \\
\hline \multicolumn{9}{|l|}{$H W: R C F$} \\
\hline $75: 25$ & $1.45 \pm 0.02$ & $378 \pm 51.2$ & $0.70 \pm 0.11$ & $34.3 \pm 2.2$ & $3.1 \pm 0.2$ & $2.9 \pm 0.3$ & $6.2 \pm 0.8$ & 2.0 \\
\hline $50: 50$ & $1.67 \pm 0.02$ & $337 \pm 41.6$ & $0.62 \pm 0.11$ & $31.2 \pm 1.7$ & $2.4 \pm 0.1$ & $2.4 \pm 0.3$ & $6.4 \pm 1.2$ & 1.2 \\
\hline $\begin{array}{l}25: 75 \\
H W: M F C\end{array}$ & \multicolumn{7}{|c|}{$H W: M F C$} & 1.2 \\
\hline $95: 5$ & $1.25 \pm 0.04$ & $139 \pm 18.4$ & $0.89 \pm 0.58$ & $48.3 \pm 8.5$ & $4.6 \pm 0.2$ & $3.9 \pm 1.27$ & $6.2 \pm 0.4$ & 3.0 \\
\hline \multicolumn{9}{|c|}{ CTMP:MFC } \\
\hline $\begin{array}{l}95: 5 \\
R C F: M F C\end{array}$ & $2.03 \pm 0.02$ & $572 \pm 56.9$ & $0.69 \pm 0.06$ & $31.9 \pm 1.6$ & $1.8 \pm 0.1$ & $2.3 \pm 0.13$ & $8.1 \pm 1.0$ & 2.0 \\
\hline $95: 5$ & $1.84 \pm 0.04$ & $101 \pm 25.0$ & $1.15 \pm 0.22$ & $30.3 \pm 1.4$ & $1.9 \pm 0.1$ & $2.1 \pm 0.20$ & $8.8 \pm 1.0$ & 0.5 \\
\hline
\end{tabular}

surprisingly low fines content of the reference board. The fines were likely joined to longer fibers even in a wet state.

Pulp mixtures: partial replacement of birch kraft pulp and its effect on 3D elongation

The 3D elongation, bulk, air permeance of the handsheet, and the fiber morphology parameters of the pulps and their mixtures used for the handsheets are shown in Fig. 3.

When the hardwood kraft was replaced with softwood kraft, the 3D elongation was greatly improved. Both of the kraft pulps had similar kink indices, and in the case of kraft pulps, fiber deformation had no influence on material extensibility. The main difference in the studied parameters was fiber length.
In the case of the CTMP, i.e. the other studied pulp with long fibers, the affect of adding the material into the hardwood pulp was the opposite to the effect of the pine kraft. Even a small amount of the CTMP decreased the 3D extensibility substantially.

Fines content of the pulp mixtures was found to increase especially when the CTMP or the RCF was added into the hardwood kraft pulp. As did CTMP, the RCF decreased 3D elongation but when only RCF was used, the 3D extensibility was higher than for the mixture of RCF and hardwood kraft even though the RCF had the highest fines content of all the pulps.

The pulp mixtures comprising pine kraft, CTMP, and RCF had average fiber length and fiber width very similar to the commercial reference sample, but the handsheets prepared using these mixtures had significantly higher 3D elongation than the reference, 


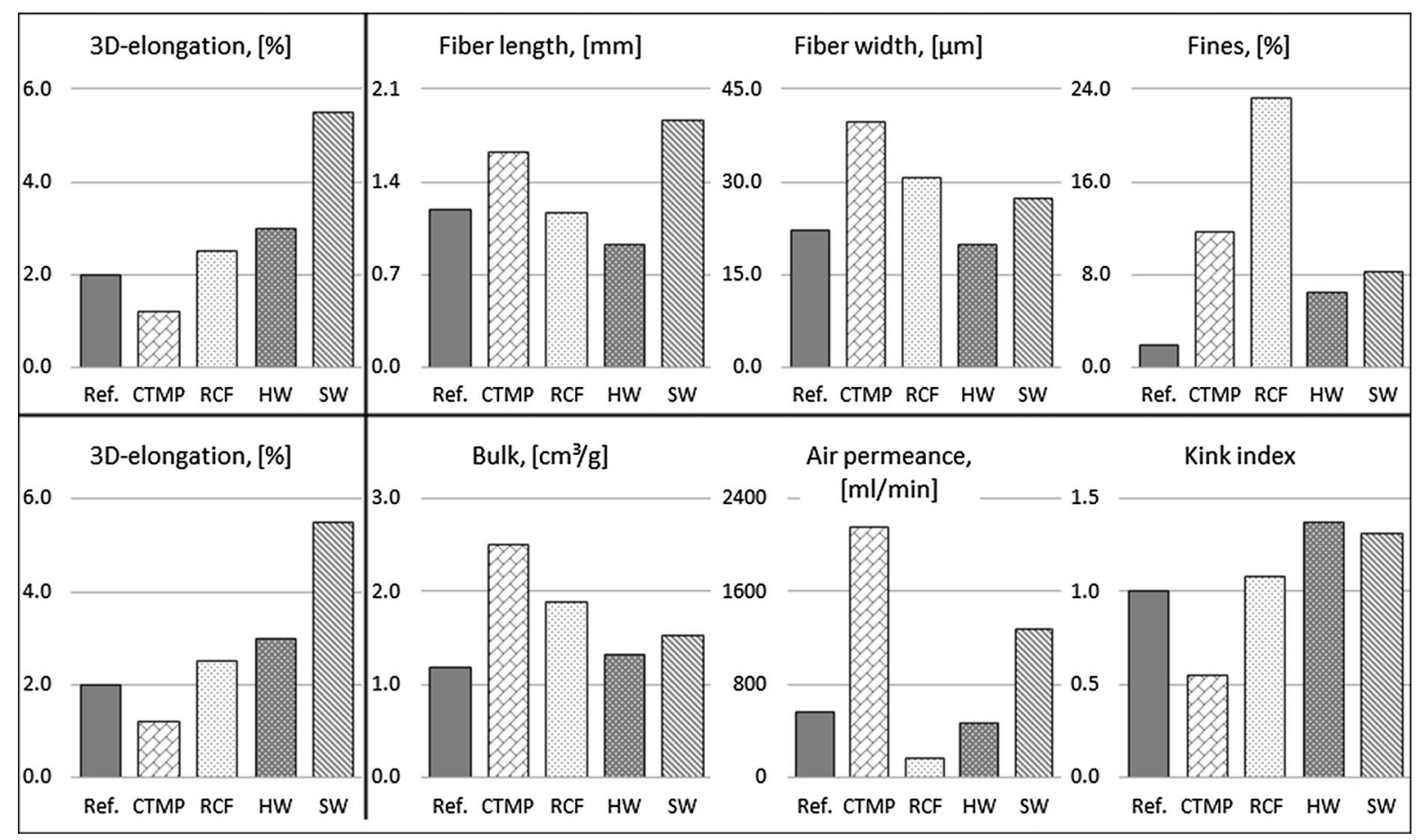

Fig. 2 Morphological properties of fibers and sheet permeance, bulk, and 3D elongation of unmixed pulps. 3D-elongation at left in both rows. All the fiber morphology results are weighed by fiber length

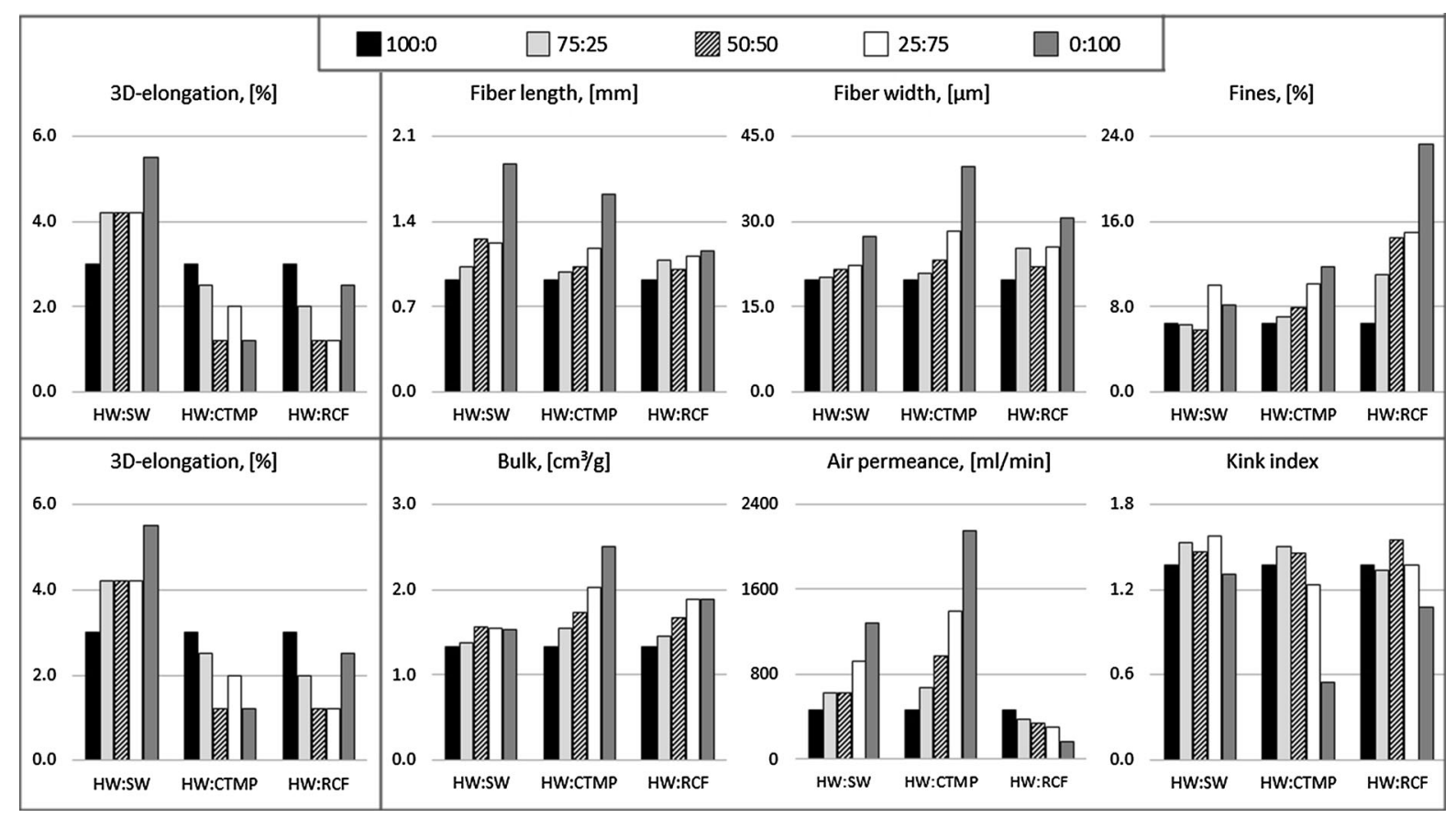

Fig. 3 Morphological properties of fibers and sheet permeance, bulk, and 3D elongation of softwood kraft, CTMP and RCF mixed with hardwood kraft. The legend shows pulp composition. 3D-elongation at left in both rows. All the fiber weighed morphology results are weighed by fiber length 
indicating that fiber dimension alone could not fully explain the 3D elongation with mixed pulp materials.

Comparison of pulps: physical properties of handsheets and 3D elongation

The physical properties of the handsheets and the commercial reference paperboard are presented in Fig. 4. The bending stiffness shows the most obvious correlation with the 3D elongation of the handsheets. When interpreting these results, it should however be stressed that, for example, high elastic modulus is also an indicator of high bending stiffness, and the presented physical properties cannot be viewed as independent variables. The effect of these properties on $3 \mathrm{D}$ elongation is discussed in more detail later. Significantly, elastic modulus was seen to affect the

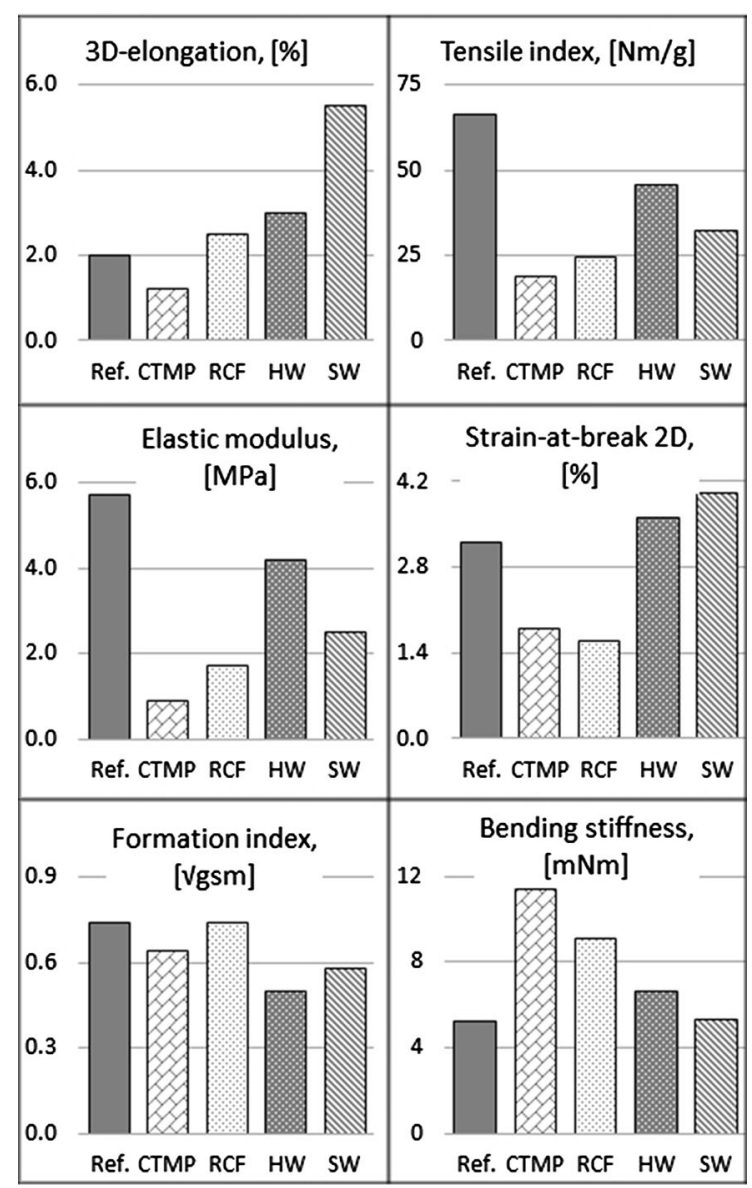

Fig. 4 Physical properties and 3D elongation of handsheets made from unmixed pulps
3D elongation with kraft pulps but the effect disappeared if CTMP was present.

When comparing the $3 \mathrm{D}$ elongation and elastic modulus of the commercial reference and the handsheets made from wood-free pulps, it can be seen that handsheets made of softwood kraft had a low elastic modulus and the highest 3D elongation. CTMP and RCF decreased sheet density somewhat, which was ascribed to the ability of the CTMP manufacturing process to preserve the native fiber stiffness and to the poor bonding capability of mechanical pulps (Nazhad et al. 2000; Pettersson et al. 2015). Differences observed in handsheet formation probably also affected the tensile properties and bending stiffness, which was higher than that of the commercial reference in all cases.

Pulp mixtures: physical properties of handsheets and 3D elongation

The physical properties of the handsheets prepared using the HW kraft based pulp mixtures are presented in Fig. 5. In the case of the mixed kraft pulps, the handsheet elastic modulus clearly affected the 3D elongation, and low bending stiffness appeared to provide extensibility. The effects of tensile index and formation on material elongation were not clear, and the strain-at-break values of the samples were quite similar regardless of the fiber composition. This observation is particularly significant, since it demonstrates the importance of conducting material testing in a real converting environment in order to obtain a realistic understanding of material performance and converting potential.

When the HW kraft was mixed with CTMP, the 3D elongation decreased dramatically. Even a small amount of CTMP impaired the material performance considerably. Bending stiffness and overall strength were found to clearly effect the 3D elongation, but the role of the elastic modulus on 3D elongation disappeared if the CTMP was present. No correlation between formation and the 3D elongation was found but the samples having good formation also had the highest tensile strength. In the case of the HW:CTMP handsheet series, strain-at-break was a relatively good indicator of 3D elongation.

As with the CTMP, RCF in the HW kraft decreased the elastic modulus and the 3D elongation of the handsheets. Within this handsheet series, the 3D 


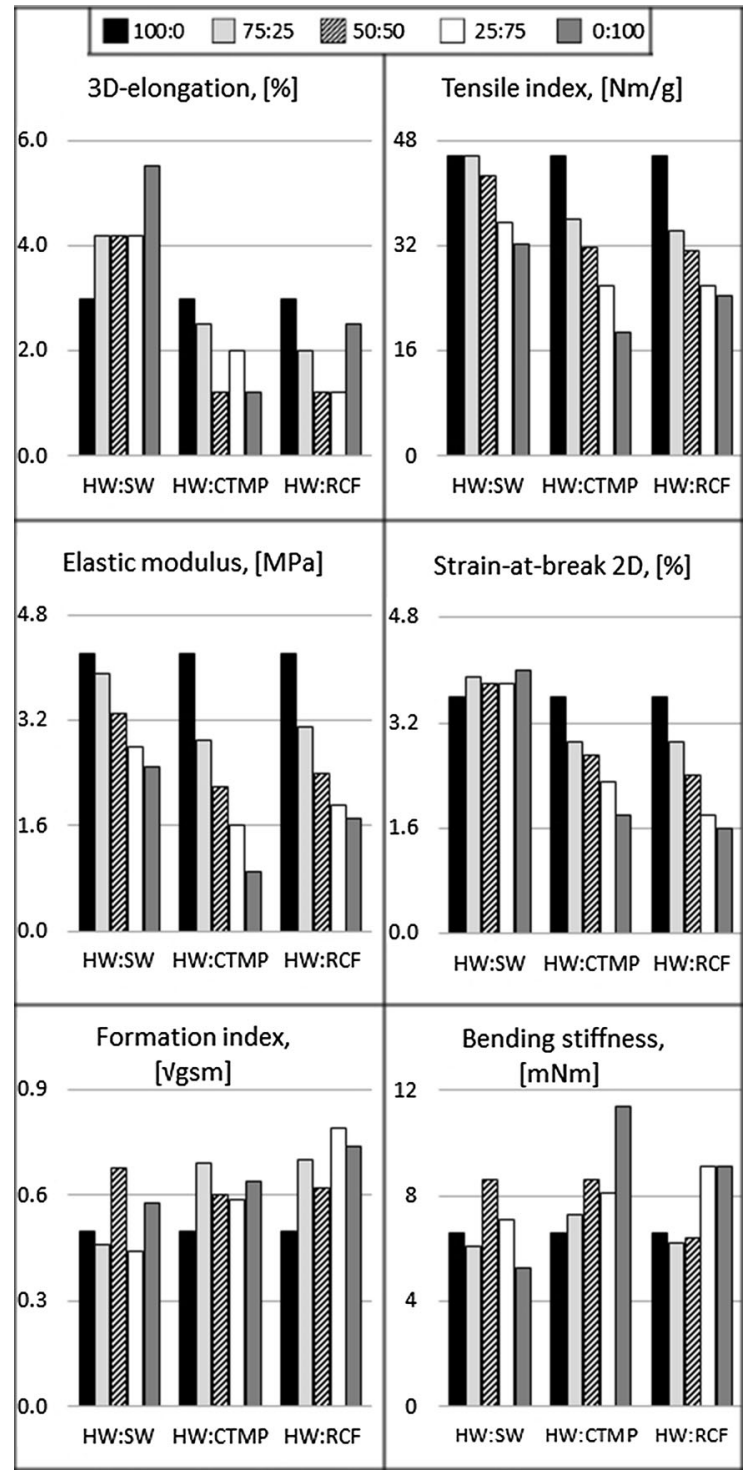

Fig. 5 Physical properties and 3D elongation of handsheets made from blended pulps

elongation did not however correlate with the elastic modulus or strain-at-break value.

Effect of microfibrillated cellulose addition

The physical properties of the handsheets prepared using HW kraft, CTMP and RCF with 5\% (wt) MFC addition are presented in Fig. 6 . With the kraft pulps, the MFC had no effect on handsheet 3D elongation, and with the CTMP, the elongation was increased only

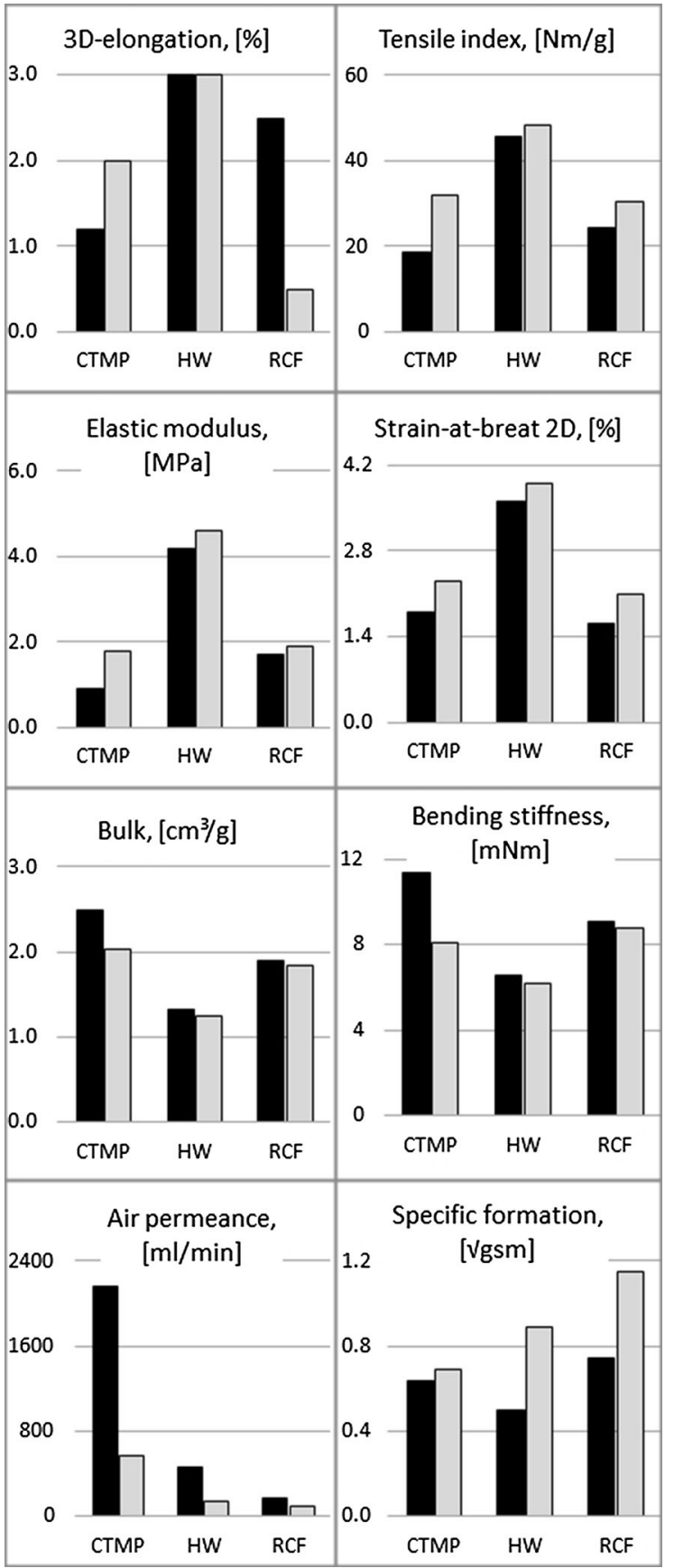

Fig. 6 Physical properties and 3D elongation of handsheets made from blended pulps. The solid black bar presents the nonblended pulp and the grey bars shows 95:5 blend of CTMP, HW or RCF with MFC

slightly. With the RCF, MFC addition resulted in a decrease in sheet extensibility. 
Tensile strength increased slightly and bending stiffness decreased, especially when the main component of the sheet was RCF or CTMP. This finding contradicts a previous study in which paper was barcoated with MFC and it was found that stiffness increased substantially (Lavoine et al. 2014).

MFC addition had only a minor effect on the elastic modulus, and bulk decreased. Change in the air permeance was significant, especially in the case of the CTMP. The poor formation, particularly in the case of the RCF, indicates limited to poor compatibility of the MFC and the other fibers.

The SEM images (Fig. 7) revealed several interesting features of the different substrates and the mechanisms behind forming-induced fractures in the pressed trays. The presence of MFC in the handsheets resulted in a smoother surface, which was also verified by Print-Parker Surface (PPS) measurements (not shown here). Addition and retention of MFC resulted in increased filling of the open areas around fiber joints and pores, although this was not seen in sheet formation. Such findings for MFC reinforced sheets have previously been reported by, for example, Petroudy et al. (2014) and Hassan et al. (2015), and the changes noted, especially those observed in the sheet properties, indicate that MFC retention took place.

The SEM images showed that despite the poorer sheet formation, the MFC dispersed relatively well, since no dense flocs were observed in the samples. In addition, the press-forming decreased the surface roughness, which was ascribed to material flattening
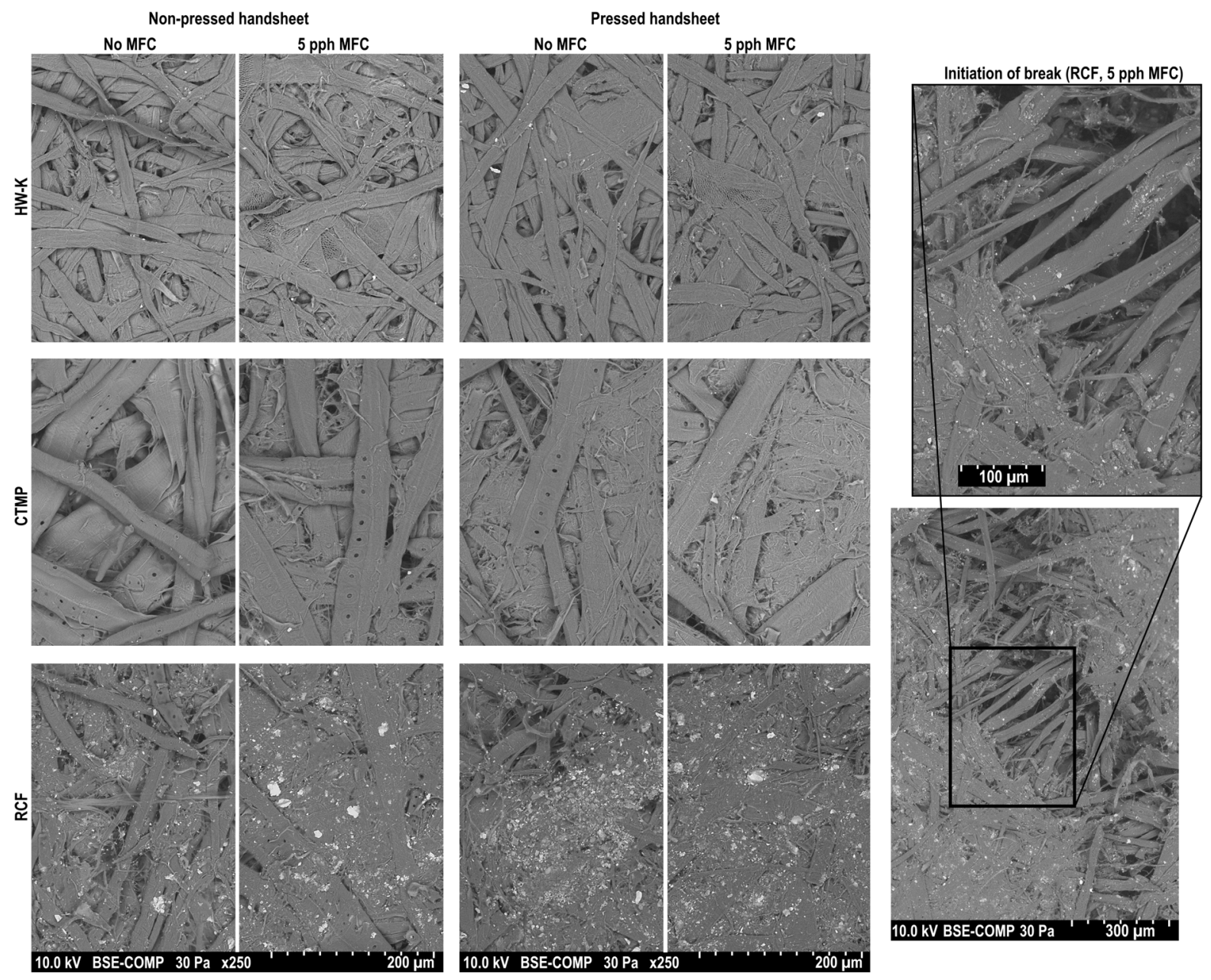

Fig. 7 SEM images of hardwood kraft (HW-K), CTMP, and RCF sheets with and without MFC addition. Images were taken from both non-converted handsheets and the bottom areas of trays 
due to mechanical forces. Surface smoothening was visible regardless of the main pulp component, and the RCF-based handsheets in particular showed surface closure after forming.

Short wood-free fiber fractions, such as chemical pulp fines and the MFC, improved fiber bonding and increased drying shrinkage, both of which should increase material elongation (Vishtal and Retulainen 2012). In this study, fracturing mechanisms and initiation of break varied depending on the pulp type. Sheets made of the mechanical pulps fractured in areas where the fines content was high, although long fibers remained relatively intact. In the case of the hardwood kraft sheets, rupturing occurred more randomly and the surface fiber fractions had no role in the emergence of the defect. This result suggests that agglomerated mechanical fines are one cause of material fractures in press-forming, and that MFC is not capable of compensating the poor bonding of mechanical fines at the dosage used in this work.

\section{Discussion}

3D elongation and fiber length

When the morphological properties of the pulps were studied, attention was focused on fiber length. A significant difference was seen in the fiber lengths of the pulps studied. Softwood kraft fibers had the longest fiber length $(1.9 \mathrm{~mm})$. For comparison, the mean length of the hardwood fibers was $0.9 \mathrm{~mm}$. According to the example given by Kajanto (2003), the strain-atbreak value measured with a tensile tester should increase $40 \%$ if fiber length is $2 \mathrm{~mm}$ instead of $1 \mathrm{~mm}$. It should be kept in mind that mechanical and chemical fines differ from each other substantially; mechanical fines comprise both fibrillar and flake-like fines with poorer bonding potential, whereas chemical fines are mostly fibrillated, which provides better bonding potential and improved sheet strength. There is also evidence that the surface of chemical fines has a relatively high lignin content and the flake-type mechanical fines originating from the middle lamella have a higher lignin content than fibrillar mechanical fines (Taipale 2010). In general, chemical pulping removes lignin effectively, which leads to lower coarseness which further makes the chemical fibers more flexible and allows curling (Paavilainen 1994).
Differences between chemical and mechanical fines are discussed in more detail by Taipale (2010).

In the present work, the percentage increase for strain-at-break and 3D elongation were $13 \%$ and $83 \%$, respectively, when the fiber length increased by $1 \mathrm{~mm}$. It thus seems that the fiber length has a major influence on the material performance in the case of wood-free pulps, implying that minimum treatment of fibers can be used to enhance the $3 \mathrm{D}$ elongaton. This finding is consistent with the work of Hauptmann et al. (2015). However, the role of the stretch-potential of individual fibers (i.e. fiber deformations such as kinks) and the degree of bonding (high beating degree of chemical pulp) should not be neglected, since the work of Seth (2005) clearly demonstrates their importance for sheet extensibility.

Significantly, with the CTMP and RCF, the calculation of the effect of fiber length on strain-at-break and 3D elongation led to a reasonable value (14\%) only in the case of strain-at-break. In 3D forming, the longer fibers decreased the material elongation by $52 \%$. It thus seems that the mean fiber length can be used as an indicator of material elongation only with kraft pulps and the functionality of this approach is limited in 3D elongation measurement. Moreover, differences in fiber length distribution width and shape suggest that it would be interesting to study handsheets made from different length fractions in order to clarify the role of fiber length in 3D elongation in detail.

Sheet consolidation potential and the development of interfiber bonds depend on pulp type and beating degree. The bonded area is smaller if a fiber network of stiff fibers is used, which together with poor formation impairs tensile properties, especially if long fibers are used (Nazhad et al. 2000). In this work, the beating levels of the wood-free pulps were kept low in order to avoid excessive creation of fines, and to minimize the loss of bulk, although this approach limited the degree of fiber plasticization (Mayhood et al. 1962). Evaluation of the effect of beating degree is a topic for further research. The results of this study, albeit only indicative, suggest that utilization of procedures to promote fiber length increase might be a functional method for 3D elongation increase when kraft pulps are used, whereas for the other pulps, different methods may be more suitable.

Other factors than fiber length are clearly at play. The poorer capability of the mechanical pulps to form interfiber bonds is well-known, which in this case is 
manifested as higher bulk and air permeance of the handsheets (and thus their limited strength) and poorer material performance in 3D forming. The mechanical fibers were also straighter than the beaten kraft pulp fibers, as seen in the kink indices. The results of Zeng et al. (2013) imply that the kink index affects paper elongation if restrained drying is applied. This suggests that the observed differences in 3D elongation of the handsheets comprising hardwood kraft and CTMP could be partly due to the CTMP fibers, which were less deformed than the hardwood fibers, whose kink index was approximately 2.5 times higher. In the case of the wood-free pulp mixtures, the softwood fibers helped to achieve higher extensibility, but long mechanical fibers did not have the same capability due to, for example, poorer bonding.

Non-deinked RCF, compatibility with hardwood kraft and paper-to-metal friction

RCF mixed with hardwood kraft exhibited curious behavior in the sense that all the mixtures showed poorer 3D elongation than either of the compounds used. The behavior in 3D forming appears even more perplexing when the other studied factors are considered, because the fiber length, fines content and other studied characteristics of the mixtures were between the values found for the hardwood kraft and RCF. The only exception was the kink index, which was higher for the mixtures than either compound. The results of Zeng et al. (2013) suggest that the opposite behavior to that found, i.e. 3D elongation increase, should be observed. In addition, the 3D elongation of the handsheets containing plain RCF was surprisingly high compared to the mixture of hardwood kraft and $\mathrm{RCF}$, and relative to plain hardwood kraft.

These two surprising findings are suspected to originate from the same factor, namely the presence of additives and ink residues in the RCF, which was not deinked. These impurities are suspected to have two different but simultaneous effects: a lubricating effect reducing friction during the press-forming, and formation of poorly bonded irregulates due to presence of hydrophobic compounds.

In forming, low paper-to-tool friction is beneficial (Vishtal et al. 2015), and oily substances such as offset inks may have acted as lubricants. In addition, water accumulated from the samples onto the tool surface. The lubricating effect of the water film that formed on the sample tool surface due to poor water reception of the RCF surface and the surface smoothess (PrintParker Surface data not shown here) may have decreased the paper-tool friction further. It is known that moisture increases the friction of paper (Kawahara et al. 2008), and it is likely that the moisture content of the RCF sheets was lower than that of the other pulps because of the less receptive surface. Table 3 gives contact angle and water droplet adsorption time data. The smoothness of the RCF-containing sheets can be ascribed to the considerable quantity of fines.

Simultaneously, it is possible that with the mixed pulps, the hydrophobic compounds found in the RCF agglomerated in the pulp suspension, resulting in hydrophobic flocs that formed poorly bonded irregularities in the fiber network between the hydrophilic birch kraft fibers and the more hydrophobic RCF fibers. This could explain the poorer 3D extensibility of the sheets comprised of both birch kraft and RCF compared to sheets containing RCF alone. The poor compatibility could also explain why the $3 \mathrm{D}$ elongation of the RCF sheets decreased when MFC was added.

The performance of the sheets made of plain RCF was however acceptable, and such a substrate seems usable if the application does not require high quality or great tray depth.

Physical properties of the handsheets and 3D elongation

The strength properties were found to affect the $3 \mathrm{D}$ elongation, but exceptions were commonly seen among the tested materials. On the whole, this was associated with the fact that the studied physical properties are partially dependent on the same factors and cannot be viewed as wholly independent variables. Bending stiffness was, however, found to be the best indicator of $3 \mathrm{D}$ elongation for the materials tested.

High bending stiffness, which was found to correlate with poor 3D formability, is indicated by high elastic modulus. High elastic modulus, in turn, is detrimental to material formability and extensibility. It can be effectively controlled by changes to the moisture content and temperature (Kajanto 2003). When comparing the 3D elongation and elastic modulus of the commercial reference and the 
handsheets made from wood-free pulps, it can be seen that the handsheets made of softwood kraft had a low elastic modulus and the highest $3 \mathrm{D}$ elongation. At the same time, however, the role of elastic modulus in 3D elongation disappeared if CTMP was present (see Fig. 5) but the correlation with bending stiffness still remained. This finding can be explained by another factor known to affect bending stiffness, namely material thickness (Ellis and Rudie 1991). The high bending stiffness of the CTMP-containing sheets was due to their thickness and not the elastic modulus, which was low with CTMP sheets. The thickness of the CTMP sheets was $600 \mu \mathrm{m}$, which means that the CTMP sheets were two times thicker than the sheets made of hardwood kraft. A similar interpretation holds true for the RCF handsheets: the presence of RCF decreased the elastic modulus, which suggests that the increase in bending stiffness was due to increased sheet thickness. The linkage between 3D elongation and elastic modulus thus seems real, but based on the results, it is not valid if the paperboard contains only mechanical pulp. Mechanical pulps increase bending stiffness due to coarse fibers that form a bulky structure with poor interfiber bonds, and this leads to a poor 3D formability. This link with thickness may also explain the previously observed correlation with bulk, as the sheets were of similar grammage.

The handsheet stiffness is also affected by fiber type. The long softwood kraft fibers decreased the handsheet stiffness substantially more than the shorter hardwood kraft fibers, as expected. Fiber length was also reflected in handsheet formation, but the effect was not as pronounced as, for example, the results of Helmer et al. (2006) would suggest. This was ascribed to different methods of producing the experimental paper and to substantial differences in grammage.

On a more general level, conflicting suggestions have been presented on whether high bending stiffness is desirable in fiber-based packaging materials. According to Ellis and Rudie (1991), high bending stiffness improves package stacking strength and thus product protection. However, high bending stiffness does not necessarily mean that the tray is stiff, and excessive blank stiffness may impair material formability in both press-forming and deep-drawing (Hauptmann et al. 2015; Ovaska et al. 2018a, b). In our case, low bending stiffness led to diagonally distorted trays when using one-layer laboratory handsheets, and the problem was accentuated with sheets made from plain softwood kraft.

\section{Effect of MFC addition on 3D elongation}

Short wood-free fiber fractions such as chemical pulp fines and MFC improve fiber bonding and increase drying shrinkage, both of which should increase material elongation (Vishtal and Retulainen 2012). The effect of microfibrillated cellulose (MFC) on paper properties has been a topic of recent interest (González et al. 2014; Ketola et al. 2018; Lavoine et al. 2014). In press-forming, however, the effect of the fines was not found be straightforward, as agglomerated mechanical fines were found to be one cause of material fractures. At the dosage used, MFC was unable to compensate the poor bonding of the mechanical fines.

The three different responses seen with MFC addition appear illogical at first glance, but when viewed more closely, the responses were found to follow the trends observed with the other materials. Significantly, a correlation between the 3D elongation and the bending stiffness was seen, except when RCF was used. In the case of RCF, the response was similar to that seen with HW:RCF and could be associated with poor compatibility, as discussed earlier. The observed decrease in bending stiffness was primarily associated with the decrease in sheet thickness, i.e. a denser fiber network, as the elastic modulus was only slightly affected.

Substantial differences in dewatering time were observed during handsheet preparation when the MFC was added. This finding was as expected. MFC addition prolonged dewatering, and mechanical fines originating from the RCF pulp had a similar effect. Slow dewatering probably affected sheet consolidation and the structure of the fiber network, since in some cases the addition of MFC impaired sheet formation. This suggests that the MFC was partly in a flocculated form in the sheets, either due to insufficient mixing of the pulp suspension or because the prolonged dewatering time led to a heterogeneous z-directional fiber component profile, which is typical for extremely fine chemical pulp (Kang and Paulapuro 2006). The trend was similar, although not as obvious, if RCF or CTMP were added to birch kraft pulp. 
Finding the optimal pulp composition

Although the required properties vary by the planned end use, and thus no single pulp composition can be claimed to be optimal for every purpose, our findings suggest that pulp mixtures can potentially be used to tailor paperboards for processes requiring $3 \mathrm{D}$ elongation. Significantly, it should be noted that the pulp resulting in the highest $3 \mathrm{D}$ formability did not result to pressed trays with the desired end used properties due to diagonal distortion. High bending strength was found to correlate with poor 3D elongation, but simultaneously high bending stiffness is required to achieve essential package properties (Ellis and Rudie 1991; Ovaska et al. 2018a, b). The diagonal distortion problem was accentuated with the sheets made of plain softwood kraft, indicating that such material alone is not only expensive but also inadequate for tray production purposes. Softwood kraft should thus be used in pulp mixtures or in multi-layered structures.

For a similar reason, the increase in bulk when pine kraft, CTMP or RCF is added to birch kraft was found to be a potentially positive change if a good quality tray rather than maximum $3 \mathrm{D}$ elongation is targeted. The use of MFC resulted in a loss of bulk with all the studied pulps, which may not be a desired change, although 3D elongation improvement was gained in some cases. With RCF, the bulk of the handsheets remained relatively unchanged, which suggests that problems related to loss of bulk can be compensated by introducing recycled fibers into the paperboard if MFC is used. However, the incompatibility of the more hydrophobic RCF with the other fibers might cause difficulties, and if impurities in the RCF are not removed, any benefit might be lost.

The performance of sheets made of plain RCF was found be satisfactory. There is evidence that the properties of recycled fibers can be tailored by refiners and dispersers (Le Ny and Messmer 2007) and the influence of mechanical fiber treatments on board performance in 3D forming should be clarified in further investigations. Although impurities present in recycled pulp limit its usage in such items as food packages, and hornification alters fiber-water interactions and strength properties (Okayama 2002), the results of the present study demonstrate the potential of RCF for use in formable materials. Discussion of possible reasons for the good performance of the plain non-deinked RCF performed presented earlier offers pointers to possible approaches for improving the behavior of boards in press-forming, as methods for smoothening boards and producing hydrophobic surfaces are well known and widely used within the industry.

Investigation of the significance of sheet formation and tensile strength suggested that these properties are not crucial for high extensibility and good formability, and therefore optimizing these properties does not need to be the main focus when pulp mixtures for $3 \mathrm{D}$ formable material are planned. This finding, however, partly contradicts the results of Hauptmann et al. (2015), who found that decreased tensile strength indicates good formability in the deep-drawing process. The difference in the findings may be due to the different deformation mechanisms in press-forming and deep-drawing. Plotting tensile strength as a function of formation or 3D extensibility, and formation against 3D extensibility (not shown here) did not reveal any correlation between the properties. This can be considered somewhat surprising, since it is wellknown that good formation is key to high tensile strength and the strain properties are defined by local variations in the fibrous network (Hagman and Nygårds 2012; Nazhad et al. 2000).

It thus seems that the role of fiber composition and fiber properties in material formability can be substantial. As the 3D elongation tests revealed, even the smallest dosage of pine kraft increased the substrate extensibility compared to samples consisting of plain birch kraft. Although the CTMP fibers were almost as long as the pine kraft fibers, their influence on the extensibility was reversed. This observation indicates that strong and long kraft fibers whose potential to form bonds is low due to low refining degree can be very useful in $3 \mathrm{D}$ forming. The results also suggest that the role of kinks on elongation potential is more important if the fiber is long, as suggested by the length and kink index of CTMP and softwood kraft given in Table 2.

\section{Conclusions}

In terms of 3D elongation, the kraft pulps were found to be superior to CTMP, RCF and the commercial reference board. For kraft pulps, increasing the fiber length appeared to be a functional method to increase $3 \mathrm{D}$ elongation, although it does not always increase 
pressed tray quality due to tray deformation. Of the studied pulp mixtures, the birch kraft and mildly beaten pine kraft resulted in the greatest 3D elongation. Despite the high price of softwood pulp, it seems to be a potential raw material for partial replacement of more common birch kraft in paperboards designed for 3D forming applications.

The performance of the CTMP and the RCF sheets was much poorer than that of the wood-free sheets but their 3D elongation did not differ substantially from the commercial reference material. It is possible that the more complex layer structure, different surface roughness and the presence of typical paper chemicals affected the 3D elongation of the commercial reference board. While a direct comparison cannot be made between the experimental paperboards and the commercial material, when considering 3D elongation, it was found that the pulps and the mixtures corresponded to a real product to some degree.

The surprisingly good 3D elongation of the RCF sheets is suspected to result from changes in the substrate-tool friction due to the chemical composition of RCF and phenomena which take place during forming. The potential of RCF in $3 \mathrm{D}$ forming was noted, but its role in pulp mixtures was found to be complex. A 5\% addition of MFC into any of the studied pulps was found to increase strain-at-break value, but the effect of MFC on 3D elongation depended on the main pulp compound. An increase in 3D elongation was seen only with CTMP.

The most important indicators for material 3D elongation were bending stiffness, elastic modulus and thickness (bulk). The magnitude of the effect of each of these properties varied and was partly dependent on pulp type. It is known that bending stiffness is affected by elastic modulus and thickness, which should be kept in mind when interpreting the laboratory results. None of the physical properties of the handsheets containing different types of pulps correlated unambiguously with the material performance.

Acknowledgments Open access funding provided by Lappeenranta University of Technology (LUT). Ms. Elizabeth Prouty (englanniksi.fi) and Mr. Peter Jones are acknowledged for language revision of the manuscript.

Open Access This article is distributed under the terms of the Creative Commons Attribution 4.0 International License (http:// creativecommons.org/licenses/by/4.0/), which permits unrestricted use, distribution, and reproduction in any medium, provided you give appropriate credit to the original author(s) and the source, provide a link to the Creative Commons license, and indicate if changes were made.

\section{References}

Alfthan J (2004) Micro-mechanically based modeling of mechano-sorptive creep in paper. Dissertation, KTH Royal Institute of Technology, Sweden, 20

Altaner CM, Thomas LH, Fernandes AN, Jarvis MC (2014) How cellulose stretches: synergism between covalent and hydrogen bonding. Biomacromol 15:791-798

Ellis RL, Rudie AW (1991) Ideal fibers for pulp and paper products. IPST Technical Paper Series (number 384), Atlanta, USA, 12

Fillinger A (2016) Hydroforming of paperboard, Circular Economy Event 2016, 2-3 February, Arnheim, German

Giacomozzi DE, Joutsimo O (2017) Drying temperature and hornification of industrial never-dried Pinus radiata pulps. 2. Voith Sulzer refining. BioResources 12:1532-1547

González I, Alcalá M, Chinga-Carrasco G, Vilaseca F, Boufi S, Mutjé P (2014) From paper to nanopaper: evolution of mechanical and physical properties. Cellulose 21:2599-2609

Gunderson DE, Considine JM (1986) Measuring the mechanical behavior of paperboard in a changing humidity environment. In: International process and materials quality evaluation conference, Atlanta, USA, September 21-24

Hagman A, Nygårds M (2012) Investigation of sample-size effects on in-plane tensile testing of paperboard. Nord Pulp Pap Res J 27:295-304

Hassan ML, Bras J, Mauret E, Fadel SM, Hassan EA, El-Wakil NA (2015) Palm rachis microfibrillated cellulose and oxidized-microfibrillated cellulose for improving paper sheets properties of unbeaten softwood and bagasse pulps. Ind Crops Prod 64:9-15

Hauptmann M, Wallmeier M, Erhard K, Zelm R, Majschak J-P (2015) The role of material composition, fiber properties and deformation mechanisms in the deep drawing of paperboard. Cellulose 22:3377-3395

Helmer RJN, Covey GH, Raverty WD, Vanderhoek N, Sardjono AA, Chau T (2006) Laboratory simulation of the effects of refining on paper formation. Appita J 59(4):291-296

Kajanto I (2003) Paper physicist's point of view to moulding of paperboard trays. In: Annual traystorming seminar, Düsseldorf Germany

Kajanto I, Kosonen M (2012) The potential use of micro- and nano-fibrillated cellulose as a reinforcing element in paper. J For 2(6):42-48

Kang TG, Paulapuro J (2006) Characterization of chemical pulp fines. Tappi J 5(2):25-28

Kawasima N, Sato J, Yamauchi T (2008) Paper friction at the various measuring conditions-effect of relative humidity. Sen'i Gakkaishi 64:336-339

Ketola A, Strand A, Sundberg A, Kouko J, Oksanen A, Salminen K, Fu S, Retulainen E (2018) Effect of micro- and nanofibrillated cellulose on the drying shrinkage, extensibility, and strength of fibre networks. BioResources 13:5319-5342 
Koubaa A, Riedl B, Koran Z (1996) Surface analysis of press dried-CTMP paper samples by electron spectroscopy for chemical analysis. J Appl Polym Sci 61:545-552

Lavoine N, Bras J, Desloges I (2014) Mechanical and barrier properties of cardboard and 3D packaging coated with microfibrillated cellulose. J Appl Polym Sci. https://doi. org/10.1002/app.40106

Le Ny C, Messmer M (2007) Potential of refining and dispersion to develop recycled fibre properties. Pulp Pap Canada 108(2):38-41

Leminen V, Tanninen P, Mäkelä P, Varis J (2013) Effect of blank holding force on the gas tightness of paperboard trays manufactured by the press forming process. BioResources 10:2235-2243

Leminen V, Ovaska S-S, Wallmeier M, Hauptmann M, Backfolk K, Varis J (2016) Effect of material properties and drawing parameters on the quality of deep-drawn paperboard products. In: 26th International conference on flexible automation and intelligent manufacturing, Soul, Republic of Korea

Linvill E, Östlund S (2014) The combined effects of moisture and temperature on the mechanical response of paper. Exp Mech 54:1329-1341

Lyytikäinen J (2015) Kartongin fysikaalisten ominaisuuksien vaikutus muovautuvuuteen. Master's thesis, Lappeenranta University of Technology, Finland, 78

Mayhood CH, Kallmes OJ, Cauley MM (1962) The mechanical properties of paper part II: measured shear strength of individual fiber to fiber contacts. TAPPI 45:69-73

Nazhad MM, Harris EJ, Dodson CTJ, Kerekes RJ (2000) The influence of formation on tensile strength of paper made from mechanical pulps. Tappi J 83(12):63-68

Okayama T (2002) The effects of recycling on pulp and paper properties. J TAPPI J 56:986-992

Östlund M, Borodulina S, Östlund S (2011) Influence of paperboard structure and processing conditions on forming of complex paperboard structures. Packag Technol Sci 24:331-341

Ovaska S-S, Geydt P, Leminen V, Lyytikäinen J, Matthews S, Tanninen P, Wallmeier M, Hauptmann M, Backfolk K (2018a) Three-dimensional forming of multi-layered materials: material heat response and quality aspects. J Appl Packag Res 10(4): 17

Ovaska S-S, Tanninen P, Saukkonen E, Backfolk K (2018b) Effect of blank pre-conditioning humidity on the dimensional accuracy and rigidity of paperboard trays. Nord Pulp Paper Res J 33(2):10

Paavilainen L (1994) Bonding potential of softwood sulphate pulp fibers. Pap Puu 76(3):162-173

Panthi, B (2016) Creasing-based creping of fiber-based substrates. Master's thesis, Lappeenranta University of Technology, 67

Petroudy SRD, Syverud K, Chinga-Carrasco G, Ghasemain A, Reselanti H (2014) Effects of bagasse microfibrillated cellulose and cationic polyacrylamide on key properties of bagasse paper. Carbohydr Polym 99:311-318

Pettersson G, Höglund H, Norgren S, Sjöberg J, Peng F, Hallgren H, Moberg A, Ljungqvist C-H, Bergström J, Solberg D (2015) Strong and bulky paperboard sheets from surface modified CTMP, manufactured at low energy. Nord Pulp Paper Res J 30(2):319-325
Rhim J-W (2010) Effect of moisture content on tensile properties of paper-based food packaging materials. Food Sci Biotechnol 19:243-247

Rhim J-W, Kim J-H (2009) Properties of poly(lactide)-coated paperboard for the use of 1-way paper cup. J Food Sci 74(2):E105-E111

Salmén L (1993) Responses of paper properties to changes in moisture content and temperature. In: Baker CF (ed) Products of papermaking, vol 1. PIRA International, Leatherhead, pp 369-430

Salmén NL, Back EL (1980) Moisture dependent thermal softening of paper, evaluated by its elastic modulus. TAPPI 63:117-120

Saukkonen E, Lyytikäinen K, Geydt P, Backfolk K (2014) Surface selective removal if xylan from refined never-dried birch kraft pulp. Cellulose 21:3677-3690

Seth RS (2005) Understanding sheet extensibility. Pulp PapCanada 106(2):33-40

Strand A, Khakalo A, Kouko J, Oksanen A, Ketola A, Salminen K, Rojas O, Retulainen E, Sundberg A (2017) The effect of chemical additives on the strength, stiffness and elongation potential of paper. Nord Pulp Paper Res J 32:324-335

Taipale T (2010) Interactions of microfibrillated cellulose and cellulosic fines with cationic polyelectrolytes. Dissertation, Aalto University, Finland, 80

Tanninen P, Kasurinen M, Eskelinen H, Varis J, Lindell H, Leminen V, Matthews S, Kainusalmi M (2014) The effect of tool heating arrangement on fibre material forming. J Mater Process Technol 214:1576-1582

Tanninen P, Matthews S, Ovaska S-S, Varis J, Backfolk K (2017a) A novel technique for the evaluation of paperboard performance in press-forming. J Mater Process Technol 240:284-292

Tanninen P, Ovaska S-S, Matthews S, Mielonen K, Backfolk K (2017b) Utilization of production-scale machine in experimental fiber material convertibility testing using a novel press-forming tool set. BioResources 12:3030-3042

Tatsumi D, Ishioka S, Matsumoto T (2002) Effect of fiber concentration and axial ratio on the rheological properties of cellulose fiber suspensions. J Soc Rheol Jpn 32:27-32

Vishtal A, Retulainen E (2012) Deep-drawing of paper and paperboard: the role of material properties. BioResources 7:4424-4450

Vishtal A, Retulainen E (2014) An approach for improved 3D formability of paper. IPW 12:46-50

Vishtal A, Khakalo A, Rojas OJ, Retulainen E (2015) Improving the extensibility of paper: sequential spray addition of gelatine and agar. Nord Pulp Pap Res J 30:452-460

Waterhouse JF (1984) The ultimate strength of paper. In: Proceedings of progress in paper physics: a seminar, design criteria for paper performance, Stockholm, Sweden, June 25-29

Zeng X, Vishtal A, Retulainen E, Sivonen E, Fu S (2013) The elongation potential of paper: how should fibres be deformed to make paper extensible? BioResources $8: 472-486$

Publisher's Note Springer Nature remains neutral with regard to jurisdictional claims in published maps and institutional affiliations. 